\title{
A construção de um aplicativo interativo como recurso didático para conceitos termodinâmicos
}

Luara Wesley Candeu Ramos luaracand@gmail.com

Universidade Tecnológica Federal do Paraná (UTFPR), Apucarana, Paraná Brasil

Bruno Rafael Del Rio brunov@alunos.utfpr.edu.b Universidade Tecnológica Federal do Paraná (UTFPR), Apucarana, Paraná, Brasil

Fernando Barreto

fbarreto@utfpredu.br

Universidade Tecnológica Federal do Paraná (UTFPR), Apucarana, Paraná Brasil

\section{José Bento Suart Júnior}

suart@utfpr.edu.br Paraná (UTFPR), Apucarana, Paraná, Brasil

\section{RESUMO}

Remetendo às animações/simulações presentes nos repositórios do PHET-Colorado e Rived este trabalho buscou a produção de um objeto de aprendizagem, especificamente animações/simulações, o qual auxilia pedagogicamente o docente em atividades de ensinoaprendizagem de conceitos de química. Para que isto fosse possível, por meio de uma pesquisa entre os docentes das disciplinas de química e engenharia química do ensino superior, foi realizado um levantamento dos possíveis modelos submicroscópicos que necessitavam de objetos de aprendizagem como auxiliares em processos de ensinoaprendizagem. Levantados os modelos em questão, os passos seguintes envolveram um processo de pesquisa em busca de uma concepção pedagógica e conceitual para os objetos de aprendizagem assim como ferramentas de programação capazes de sustentar tais concepções. Assim, utilizando a ferramenta GDevelop para sua concretização, em face aos relatos apresentados o aplicativo "Processos Termodinâmicos" foi desenvolvido, sendo o mesmo composto de três módulos, oferecendo conceitos sobre: processos endotérmicos e exotérmicos, sistema fechado e adiabático, solvatação, entropia e entalpia. Os módulos apresentam conteúdos autoexplicativos que são abordados pelo "Termo" um personagem/instrutor, que propões algumas relações entre os conteúdos no processo de ensino-aprendizagem tendo, por conseguinte, total consonância com as necessidades desveladas pelos docentes referentes ao levantamento realizado.

PALAVRAS-CHAVE: Objeto de aprendizagem. Processos termodinâmicos. Gdevelop. TIC. 


\section{INTRODUÇÃO}

A revolução eletrônica, com uso frequente de computadores e internet, permitiu a abertura para aprendizagem por meio da exploração e descoberta. Neste contexto, é inegável que as Tecnologias de Informação e Comunicação desempenham um papel fundamental nos novos direcionamentos para cultura, comunicação e educação, tornando-se, portanto, ferramenta importante no processo de ensino-aprendizagem. Mas, explorar as possibilidades tecnológicas no contexto ensino-aprendizagem constitui um desafio para os professores. Frequentemente, em situações de ensino, as dificuldades encontradas por alunos na aprendizagem são decorrentes da adoção de estratégias e abordagens equivocadas. A utilização de objetos de aprendizagem (OAs) surge como uma alternativa pedagógica para contornar algumas dessas dificuldades. A introdução das Tecnologias de Informação e Comunicação (TIC) na prática escolar, quando mediada pelo trabalho colaborativo e reflexivo na presença de um profissional experiente no uso da informática, pode efetivamente desencadear um processo de mudança da cultura docente e escolar trazendo melhorias na aprendizagem do aluno.

Como ilustram Couto e Coelho (2013), para que a escola possa construir práticas mediadas pelas TIC é necessário constituir redes e políticas que favoreçam a melhoria do processo de ensino e aprendizagem, numa dimensão globalizante (re)pensando sua estrutura que ainda é linear, anacrônica, com tempos e espaços delimitados numa lógica que parece não atender as condições de aprendizagem no mundo contemporâneo.

A Tecnologia de Informação e Comunicação aplicada à Educação não promove mudanças se o professor não compreender que construir conhecimento na era digital requer constante atualização. Neste contexto, os saberes pedagógicos e os dos conhecimentos na formação do professor necessitam contemplar as concepções e a utilização de tecnologias, e proporcionar ao professor o uso das tecnologias de comunicação e de informação no seu dia a dia de forma consciente. A utilização das TICs, no contexto escolar como efetiva ferramenta de ensino facilitadora da aprendizagem dos alunos, amplia a intervenção do formador na busca de novas estratégias e na criação de novos caminhos que possam favorecer a reconstrução da prática pedagógica do professor no uso da tecnologia na Educação (MISKULIN et al, 2006).

A química computacional já vem sendo desenvolvida no seio das universidades como uma alternativa para a pesquisa em química, sendo reconhecida como área de pesquisa teórica. Contudo, explorar as possibilidades tecnológicas educacionalmente constitui um desafio para os professores em virtude das dimensões epistemológicas, culturais, sociais, políticas e acadêmicas implicadas.

A ineficiência das abordagens tradicionais e mecanicistas denotam urgência e aclamação por novas tecnologias. No entanto, a busca por tecnologias de informação e comunicação ligadas ao ensino de conceitos químicos aponta lacunas em relação à construção de TICs e avaliação das mesmas em contexto educacional. Ainda assim, a potencialidade destas no ensino de química, ou no ensino em geral, indicam que existem definitivos ganhos em aprendizagem, que ocorrem devido à formação de uma díade entre o computador e o aluno. 
Finalmente, a introdução de tecnologias da comunicação e informática na educação está atrelada primordialmente à busca de soluções para promover melhorias no processo de ensino-aprendizagem, já que utilizados adequadamente, podem favorecer a motivação dos alunos e transformar a prática docente dos professores, dando-Ihes oportunidades de trabalhar com atividades dinâmicas e motivadoras. Como abordado por Costa e Fiorentini (2006), professores passam a ser concebidos como comunicadores, reflexivos, investigadores e articuladores de mídias diversas, inseridos no meio urbano de diversidade cultural.

Neste contexto, dentre as diversas tecnologias de informação e comunicação destaca-se o uso de objetos de aprendizagem em processos de ensinoaprendizagem.

\section{OBJETOS DE APRENDIZAGEM E O ENSINO DE QUÍMICA}

Um objeto de aprendizagem se configura como uma construção virtual, programada, que organiza imagens virtuais formando um constructo de informações e saberes cujo objetivo é facilitar o processo de ensino-aprendizagem.

Qualquer material didático envolvendo conteúdos, interdisciplinaridade, exercícios e complementos sob recursos tecnológicos, pode ser considerado um Objeto de Aprendizagem (OA). Um OA é uma das novas possibilidades que as TIC's representam, podendo conter simples elementos como um texto ou um vídeo, um hipertexto, um curso ou até mesmo uma animação com áudio e recursos mais complexos. Em virtude disto, qualquer docente pode utilizar esses mecanismos na produção do conhecimento. Entretanto, os objetos de aprendizagem devem ser utilizados por todos os envolvidos (professores, estudantes e desenvolvedores), não apenas como novos objetos educacionais, mas como recursos potencializadores do processo de ensino aprendizagem.

Para explicar o conceito de Objetos de Aprendizagem, Hodgins (apud Wiley, 2000) apresentou a Metáfora do Lego. Nesta analogia, os OAs são comparados às peças do brinquedo infantil conhecido como Lego, em que pequenos blocos encaixáveis unidos a outros blocos podem ser reutilizados em diversas combinações formando estruturas. Mas, Wiley (2002) aponta limitações na metáfora do Lego. Segundo ele, esta metáfora consegue explicar de maneira simples a ideia de que os Objetos de Aprendizagem são "pedaços de instrução". No entanto, esta ideia é limitada, pois há propriedades inerentes aos blocos de encaixe que não podem ser relacionadas aos OA's.

Wiley (2000) utiliza então a metáfora de um átomo para explicar o objeto de aprendizagem. Ele explica que um átomo é um elemento pequeno que pode ser combinado e recombinado com outros elementos. Ou seja, cada objeto de aprendizagem pode constituir-se em um módulo com um conteúdo autoexplicativo, sendo esse uma breve explicação do conteúdo abordado pelo OA. Este também pode ser direcionado a outros módulos para formar um curso mais abrangente estando dentro do mesmo contexto, isto é, relacionando conteúdos.

A teoria instrutiva "Learning Object Design and Sequencing Theory" (LODAS) de Wiley (2000) é descrita por meio de objetivos, valores, condições e métodos. Os objetivos verificam o uso do OA em relação ao contexto do projeto instrutivo, fornecendo a sustentação explicita para o design, reuso e domínio de conteúdo 
baseado na revisão da literatura. Por conseguinte, os valores estão relacionados com as características desejadas pela teoria, seguido das condições para a aplicação da teoria, a qual deve determinar uma motivação para as necessidades do aprendiz, o estilo do instrutor, o ambiente de aprendizagem e os objetivos instrutivos. Os métodos são resumidos em 5 categorias com conteúdos relacionados inseridos no mesmo contexto: Atividades preliminares; Análise e síntese do conteúdo; Apresentação da prática e da informação do design; Seleção e/ou projeto do OA; Melhoria da qualidade do OA. Wiley (2000) entende que os objetos de aprendizagem devem ter as seguintes características: serem autoexplicativos, modulares, agregáveis, digitais, interoperáveis e reutilizáveis.

Kemezinski et al. (2012) descrevem uma metodologia para a construção e avaliação de um Objeto de Aprendizagem composta por 6 etapas (Análise, Projeto, Implementação, Submissão, Avaliação e Publicação) cujo principal objetivo é atender as características técnicas e pedagógicas da concepção à avaliação dos objetos de aprendizagem. A Análise fornece um suporte para construí-lo de forma a garantir as seguintes características pedagógicas: interatividade, autonomia, cooperação, cognição, afeto. A etapa do Projeto se concentra nos detalhamentos específicos do OA. Após a implementação, cabe ao responsável submeter o objeto à um repositório para avaliação e posterior disponibilização do mesmo para o público em geral.

Um objeto de aprendizagem considerado bem estruturado é basicamente dividido em quatro partes. A primeira se refere a definição dos objetivos do material instrucional, fazendo um levantamento das limitações para estimar como e o que pode ser aprendido além de tomar conhecimento da aplicação do mesmo. A segunda parte refere-se ao conteúdo instrucional, ou seja, o desenvolvimento da produção do material didático. Subsequentemente deve ser realizada uma ambientação prévia sobre a capacitação do processo de ensino-aprendizagem, a terceira etapa. Por fim, faz-se um acompanhamento de todo o desenvolvimento do $\mathrm{OA}$, caracterizando uma revisão, afim de responder à pergunta "O desempenho do objeto de aprendizagem atingiu as expectativas?", para que a partir da resposta obtida avalie-se o objeto.

Contudo, ainda que estratégias possam ser delineadas para o desenvolvimento e implementação de um objeto de aprendizagem, o professor se caracteriza como a melhor tecnologia educacional disponível, devendo ele trazer consigo aspectos teórico-metodológicos a respeito da implementação da tecnologia no contexto educacional e suas influências na prática pedagógica, proporcionando a imersão no mundo digital e a criação de uma nova cultura.

Atualmente, o uso dos recursos tecnológicos para incentivar a motivação dos alunos é de suma importância, dando aos professores a oportunidade de transformar a prática docente com atividades dinâmicas e motivadoras. Artigos científicos, capítulos de livro e até mesmo obras inteiras dedicadas ao tema Objeto de Aprendizagem apontam ganhos na aprendizagem quando se utiliza uma TIC de forma adequada.

Considerando-se o contexto das tecnologias de informação e comunicação e o uso de objetos de aprendizagem, este trabalho apresenta o processo de produção de uma animação/simulação interativa, remetendo a objetos apresentados pelas plataformas da Universidade do Colorado (PHET-Colorado) e do Rived. 
O objeto de aprendizagem aqui apresentado foi configurado via linguagem HTML 5 usando a ferramenta GDevelop de animações interativas, que possibilita o controle das variáveis em questão e, consequentemente, o curso do fenômeno em estudo a partir deste controle, remetendo assim a modelos teóricos submicroscópicos de conceitos Químicos como forma de manipular tais variáveis e compreender a estruturação do próprio modelo em relação a suas proposições. Neste sentido, configura-se como um recurso que permite a articulação dos três níveis representacionais dos conceitos químicos: macroscópico, submicroscópico e simbólico. Assim, este trabalho tem como objetivo a apresentação dos resultados referentes à produção de um aplicativo interativo para modelos teóricos submicroscópicos aplicáveis como recurso didático no desenvolvimento de estratégias de ensino-aprendizagem para termodinâmica.

\section{METODOLOGIA}

O objeto de aprendizagem aqui apresentado foi construído no interior de um projeto de Recursos Educacionais Abertos propiciado pela Universidade Tecnológica Federal do Paraná. O projeto que viabilizou a construção do OA contou com a participação de dois alunos de graduação, sendo um do curso de Engenharia Química e outro de Licenciatura em Química do Campus Apucarana, e dois docentes, sendo um da área de ensino de ciências e outro da área computacional.

A construção do objeto de aprendizagem aqui apresentado ocorreu em duas etapas: levantamento bibliográfico para sondagem das produções acadêmicas referentes a objetos de aprendizagem e construção colaborativa entre bolsistas e orientadores.

A construção do objeto de aprendizagem ocorreu de forma dinâmica a partir de um questionamento inicial foi realizado buscando as principais necessidades dos docentes dos cursos supracitados em relação a dificuldades pedagógicas em processos de ensino-aprendizagem visando identificar possíveis animações/simulações que poderiam se comportar como meios potencializadores. Desta forma, todo o processo de construção visou adaptar o objeto de aprendizagem às dificuldades reais de ensino-aprendizagem dos conceitos identificados em relação às próprias estratégias dos docentes questionados.

O processo de construção se deu via associação entre dois bolsistas, sendo um responsável pela concepção conceitual e pedagógica do objeto de aprendizagem, remetendo a um processo intenso de pesquisa a artigos e outros recursos que permitam, a partir da área de Ensino de Química, enquanto ao outro coube a construção computacional do objeto em consonância com o conhecimento produzido sobre os processos de ensino-aprendizagem destes conceitos. Isso tornou todo o processo retroalimentativo em relação à utilização, avaliação, abordagem pedagógica e conteúdo do objeto de aprendizagem.

O objeto de aprendizagem em questão direcionou-se para a utilização em processos de ensino-aprendizagem de conteúdos de Química e pode ser integrado em sequências didáticas embasadas na metodologia de solução de problemas. Buscou-se o desenvolvimento de simulações de modelos que permitiriam o estudo e compreensão dos conjuntos teóricos sobre os quais os modelos se embasam, assim como a interligação entre as variáveis que compõem os próprios modelos e o papel destas no comportamento dos modelos. Desta forma, comportou-se como 
meio de construção de conhecimento científico, não apenas em relação aos conteúdos, mas ao próprio processo de construção de modelos teóricos em Ciências.

\section{RESULTADOS E DISCUSSÕES}

O incremento das novas Tecnologias da Informação e Comunicação, vem demonstrando ser uma poderosa aliada para a melhoria no processo de ensinoaprendizagem. Devido à grande quantidade de conceitos abstratos e complexos existentes na Química, as TICs demonstram ser uma ferramenta vital para o processo de ensino-aprendizagem. Com isso as novas tecnologias proporcionam oportunidades para a utilização de ambientes de aprendizagem que ultrapassam as possibilidades das tecnologias mais tradicionais. Um exemplo disso são os Objetos de Aprendizagem (OA). Neste contexto, o Objeto de Aprendizagem "Processos Termodinâmicos" foi criado a fim de ajudar o professor a desenvolver, no decorrer de sua aula, a "visão submicroscópica" do aluno, facilitando assim sua compreensão dos conceitos de gás ideal, reações exotérmicas e endotérmicas, combustão, sistema fechado, adiabático, solvatação e entropia.

A seguir relata-se o contexto sobre o qual foi desenvolvido o objeto de aprendizagem e posteriormente sua concepção, finalidade, especificidades e também adversidades na utilização da ferramenta GDevelop para sua concretização.

\section{O PANORAMA DAS PESQUISAS SOBRE OBJETOS DE APRENDIZAGEM}

Procurando desenvolver um panorama sobre a produção bibliográfica dos objetos de aprendizagem, esta pesquisa analisou os artigos de periódicos nacionais on-line com avaliação Qualis-Capes A1, A2, B1 na área de Ensino. É valido ressaltar que textos como: apresentações editoriais, resenhas, resumos de livros, e outros não artigos, não caracterizados como produto de pesquisa, foram desconsiderados. Portanto, foram analisados 90 artigos, de modo que nas linhas de pesquisas: ensino de ciências; ensino de física e ensino de química contabilizouse 15 artigos ao final das análises.

A nomenclatura utilizada nos artigos foi diversificada, com termos tais como: material, materiais instrucionais, experimentais, digitais, pedagógicos e informáticos (DUARTE, 2012; SOUSA; MALHEIROS; FIGUEIREDO, 2015; FERNANDES; RODRIGUES; FERREIRA, 2015; COUTO; COELHO, 2013; PAGNOSSIN et al, 2014; BETZ; LIMA; MUSSATTO, 2009). Frente a variedade de termos, a utilização do nome objeto de aprendizagem não é irrevogável, ficando a cargo do leitor ou pesquisador a utilização deste ou de outro termo.

O ensino de ciências possui caráter interdisciplinar, envolvendo conceitos biológicos, físicos e químicos intricados em seu currículo, porém foram alocados apenas 3 artigos na linha de pesquisa "ensino de ciências". O primeiro, referente ao estudo sobre conceitos interativos na disciplina de Dinâmica do Movimento dos Corpos. Os objetivos do desenvolvimento dos OAs nesse contexto eram: adotar e difundir recursos pedagógicos que pudessem favorecer o pensamento crítico, a descoberta e a verificação prática de como os conteúdos de uma disciplina de 
ciências poderiam ser aplicados em situações hipotéticas que aproximam o estudante da realidade, e determinar diretrizes e estratégias de desenvolvimento e implementação que pudessem promover a participação e a aprendizagem autônoma dos estudantes (PAGNOSSIN et al., 2014). O segundo sobre astronomia, objetivou desenvolver uma sequência didática para o ensino das estações do ano, das atividades propostas em alguns momentos o professor utilizou recursos como o globo terrestre e bolas de isopor (TAXINI et al, 2012). Estes recursos de fácil aquisição e comuns ao ambiente escolar podem desempenhar papel importante no processo de ensino-aprendizagem. $O$ último fornece um ponto de partida para a construção e a implementação de uma abordagem didática e mediada pelas TICS, para a aprendizagem de Ciências por meio de Módulos Temáticos Virtuais (MTVs), o uso de repositórios, objetos de aprendizagem, por meio do estímulo do professor/mediador, principalmente durante o levantamento de hipóteses e as interações realizadas com os recursos digitais (FERNANDES; RODRIGUES; FERREIRA 2015).

Os artigos relacionados ao ensino de física foram categorizados em astronomia, eletromagnetismo, mecânica, ondas e termodinâmica, totalizando 10. Os periódicos com maior número de artigos publicados sobre objetos de aprendizagem são do ensino de física e outra característica relevante levantada entre os artigos é a abordagem de recursos de baixo custo na sua elaboração. (LABURÚ; SILVA; BARROS, 2008; LOPES; STEIN-BARANA; MORENO, 2009; MUNHOZ; STEIN-BARANA; LEME, 2012; REIS; GARCIA; BALDESSAR, 2012).

Objetos manuais, palpáveis, demonstraram possibilidades de inclusão em relação a óptica e astronomia, em trabalhos voltados para a inclusão, nos quais objetos são direcionados a facilitar a construção dos conceitos por assimilação de um determinado fenômeno ou mesmo parte dele (DOMINICl et al., 2008).

O subgrupo de eletromagnetismo apresentou a maior quantidade de artigos. Laburú, Silva e Barros (2008) tratam do mecanismo de demonstração de eletrização e cargas eletrostáticas. Lopes, Stein-Barana e Moreno (2009) demonstram a construção e utilização de um guindaste eletromagnético, enquanto Sousa, Malheiros e Figueiredo (2015) relacionam conceitos à força de Lorentz com movimentos de cargas num campo magnético;

Entre artigos que possuem propostas envolvendo a produção de animações tridimensionais modeladas por computador, direcionadas ao ensino de física, foram encontrados, Veraszto et al. (2015) e Lagreca et al. (2012), voltados ao subgrupo da matéria mecânica. Os demais artigos referem-se a mecânica quântica e ondulatória como Sales et al. (2008) que representa uma metáfora do efeito fotoelétrico e possibilita o cálculo da constante de Planck. Por fim tem-se Betz, Lima e Mussato (2009) cujo material está organizado em um elemento central, que se trata de uma animação interativa e comentada. Neste trabalho, o instrumento permitiu discutir a clássica questão do caminho seguido pelo fóton. A animação apresentou as visualizações dos ingredientes que fundamentam as descrições teóricas, tais como frentes de onda, deslocamentos de fase, sobreposições e separações de pacotes em componentes.

Nas linhas do ensino de química foram indexados trabalhos que se aproximam bastante de atividades estritamente experimentais como o texto de Sartori e Loreto (2008), que propõe uma simulação experimental, utilizando materiais acessíveis e de baixo custo, sobre o mecanismo biofísico da visão das cores em 
conformidade com a teoria tricromática de Young-Helmholtz, abordando, principalmente, o processo de codificação e decodificação de sinais elétricos que chegam ao córtex cerebral. Já no artigo de Benite e Benite (2008), os autores relatam uma reflexão, em bases sócio históricas e culturais, sobre a compreensão das potencialidades e limitações do uso do computador para o ensino de química além de considerações gerais referentes às primeiras experiências desta utilização.

O levantamento bibliográfico mostrou que o contexto acadêmico de produção de objetos de aprendizagem voltados para o ensino de química é escasso em publicações dirigidas, tornando pertinente o desenvolvimento estruturado do objeto proposto dentro do projeto de recursos educacionais.

A seguir encontra-se a descrição do objeto de aprendizagem produzido pelos autores deste trabalho, seu funcionamento, potencialidades e limitações.

\section{OBJETO DE APRENDIZAGEM PARA CONTEÚDOS DE QUÍMICA: PROCESSOS TERMODINÂMICOS}

A química é considerada por muitos estudantes como uma ciência complicada e difícil de compreender. Johnstone (1982, apud WARTHA; REZENDE, 2011), em seu artigo "Macro and micro-chemistry", foi um dos primeiros pesquisadores a propor um modelo de pensamento em química, um triângulo com três ideias principais que consiste em três modos denominados "modos de representação": macroscópico, submicroscópico e simbólico.

O nível macroscópico, nível sensorial ou perceptivo, é o real e o concreto, correspondendo aos fenômenos químicos observáveis, que podem ou não ser parte das experiências diárias dos estudantes, mas que podem ser observados, dentre diversas formas, por meio de experimentos. O nível submicroscópico representa as formas particuladas da matéria que podem ser usadas para descrever o que é observado macroscopicamente, por exemplo, o movimento de elétrons, moléculas, partículas e átomos. O terceiro nível, simbólico, corresponde ao representacional, através do uso de equações químicas, equações matemáticas, gráficos, mecanismos de reação, analogias e modelos. A observação dos fenômenos, a representação dos fenômenos e seu entendimento no conjunto destas três ideias traz o verdadeiro entendimento e domínio do conhecimento químico (WARTHA; REZENDE, 2011). 
Figura 1- Triângulo de Johnstone com seus três níveis representacionais

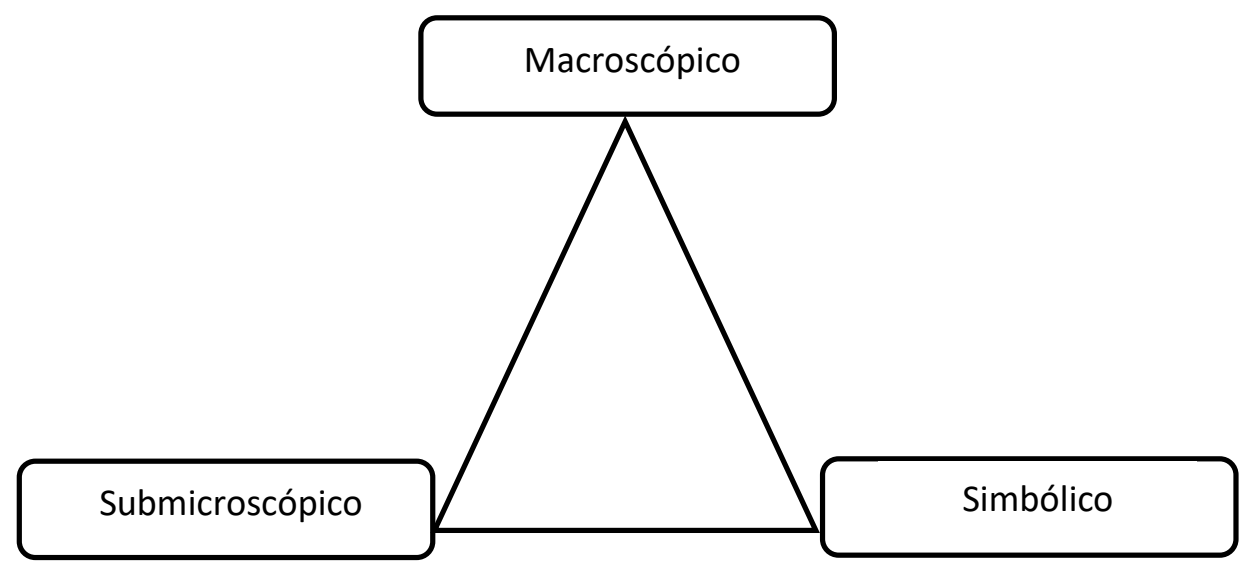

Fonte: Adaptado de WARTHA; REZENDE (2011).

Johnstone verificou inconsistências no modelo proposto e, 10 anos depois, apresenta uma nova versão para seu modelo com algumas alterações, agora denominado "componentes de uma nova Química" e que, em um novo artigo passa a denominá-lo de "formas de uma natureza para a Química". Os componentes da nova Química seriam a macroquímica do tangível, do concreto, do mensurável; a submicroquímica do molecular, do atômico e cinético; e uma Química do representacional que corresponde aos símbolos, às equações e fórmulas químicas (WARTHA e REZENDE, 2011).

Johnstone recomenda que os professores de química criem situações reais que possam mostrar o universo macroscópico ao aluno acompanhado da simbologia química pertinente e que, ao mesmo tempo, se utilize de diferentes tipos de figuras, tais como animações de computador e simulações, com o objetivo de criar habilidades para a compreensão do nível molecular. Uma vantagem em usar ferramentas multimídia no ensino e aprendizagem de química é o múltiplo sistema de símbolos e representações que elas apresentam e que podem levar a um entendimento completo dos conteúdos. Estudos mostram que o uso combinado de texto e figuras animadas torna a informação mais fácil de ser memorizada, além do que essas ferramentas multimídia podem auxiliar no ensino e aprendizagem de química por desenvolver habilidades espaciais e percepção de modelos (WARTHA; REZENDE, 2011).

Como a maioria dos conceitos e explicações de fenômenos químicos estão relacionados ao mundo submicroscópico, que é invisível aos estudantes, a compreensão da química se dá pelo uso de símbolos. Em geral, a dificuldade se encontra em entender os fenômenos químicos e construir modelos mentais sobre esses fenômenos. Em vista disso, o objeto de aprendizagem "Processos Termodinâmicos" foi construído com base em pesquisa em periódicos, sites e livros, sobre as concepções de termodinâmica e estudo dos gases. Este, traz uma nova forma de uso da tecnologia em sala de aula bastante flexível, e de fácil adaptação.

A seguir, relata-se a estrutura e funcionalidade do objeto desenvolvido. 
Figura 2 - Capa do OA processos termodinâmicos

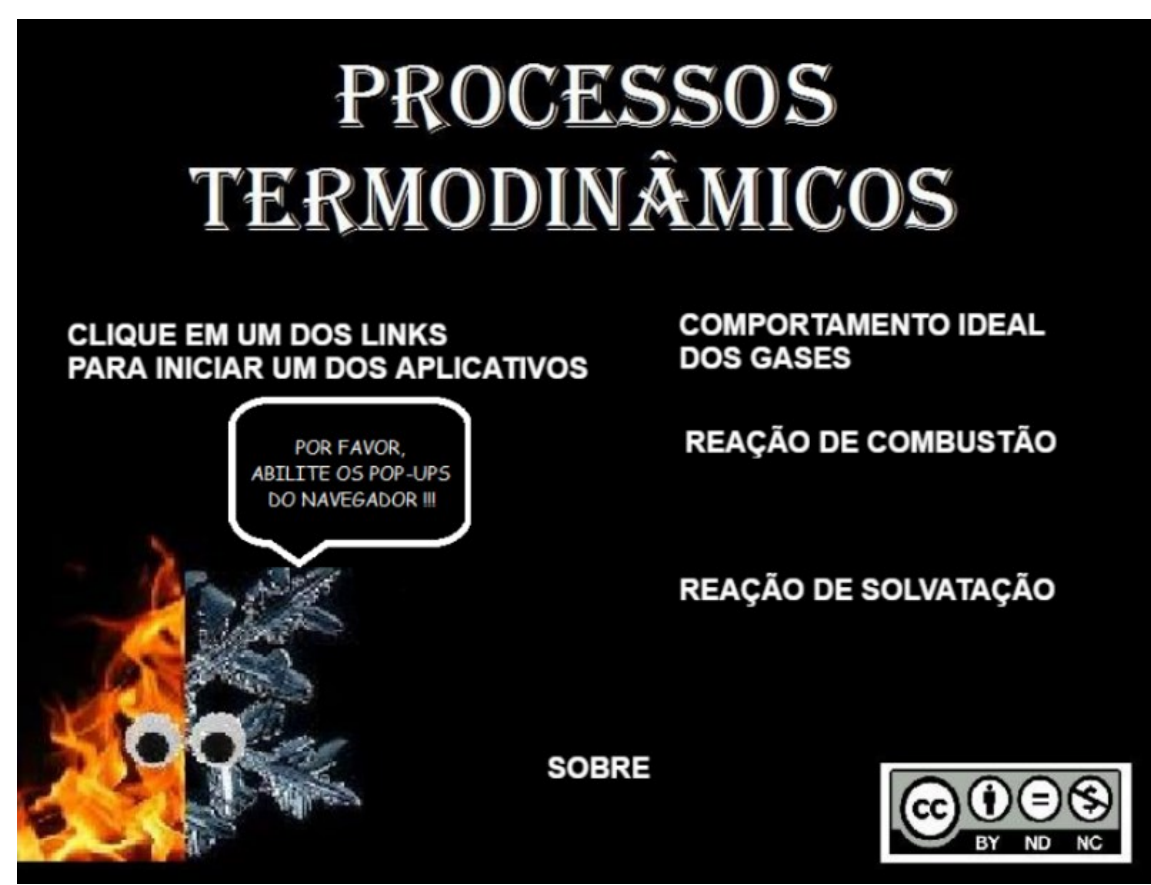

Fonte: Print Screen do aplicativo (2017).

O objeto de aprendizagem apresenta 3 módulos os quais oferecem representações conceituais para: processos endotérmicos e exotérmicos, sistemas fechado e adiabático, combustão, solvatação, entropia e entalpia. Os módulos apresentam conteúdos autoexplicativos que são abordados pelo "Termo" um personagem/instrutor, que propõe relações entre os conteúdos no processo de ensino-aprendizagem. As inter-relações em seus módulos ajudam a compreender os conceitos abordados, auxiliando o aluno a construir uma visão submicroscópica.

Figura 3- módulos presentes no objeto de aprendizagem
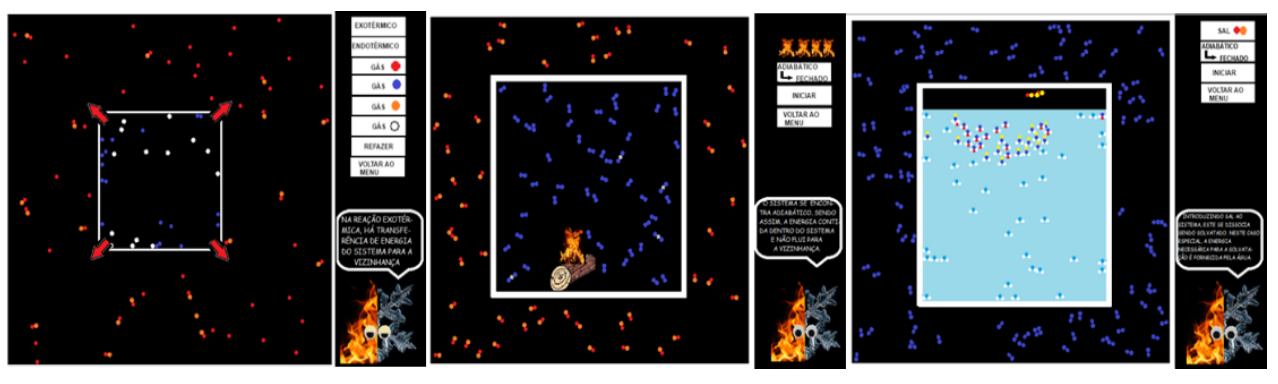

Fonte: Print Screen do aplicativo (2017).

O primeiro módulo, "Comportamento ideal dos gases", traz processos exotérmicos e endotérmicos a partir de trocas de energias. A termodinâmica é a ciência que se dedica ao estudo das trocas de energia que acompanham as transformações químicas e físicas da matéria. Conforme Atkins e Jones (2006): naturalmente em duas partes. A primeira Lei preocupa-se em observar as variações de energia e, permite-nos calcular, por exemplo, quanto calor uma reação produz. A segunda Lei, explica porque algumas reações ocorrem, mas outras não. (ATKINS; JONES 2006, p.341)". 
Figura 4-módulo 1: reações exotérmicas e endotérmicas
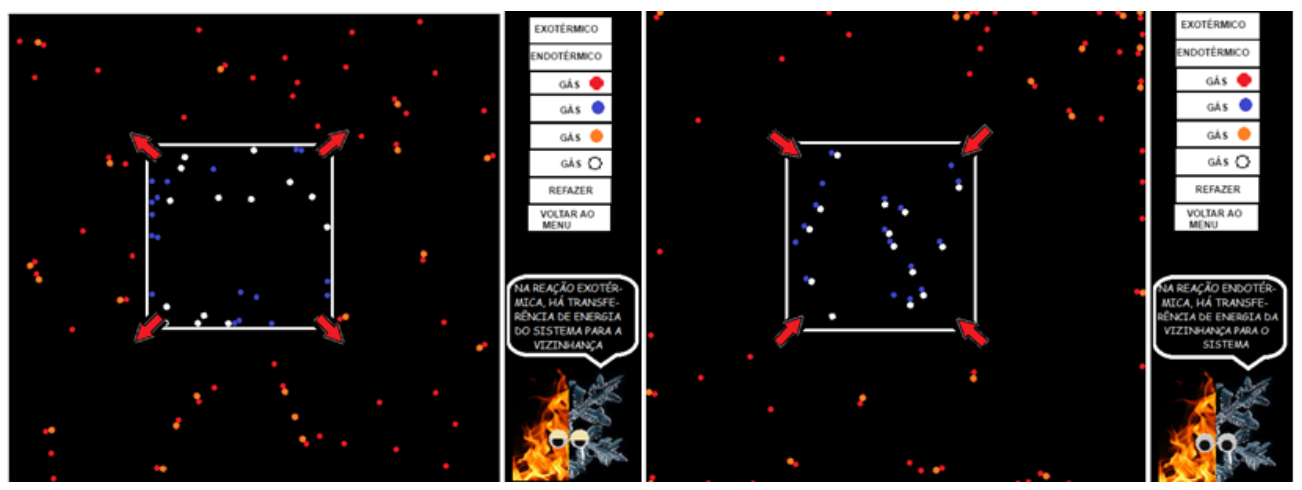

Fonte: Print Screen do aplicativo (2017).

Nas reações químicas há variação de temperatura do sistema reacional ocasionada por variação de energia que acompanha as reações. Devido a essa variação o sistema pode sofrer aumento ou perda de energia. Quando a reação libera energia do sistema para a vizinhança, trata-se de um processo exotérmico. Quando a reação absorve energia, há troca de energia da vizinhança para o sistema, dizemos que se trata do processo endotérmico.

Como a energia pode ser transformada de uma forma para outra e transferida de um lugar para outro, em termodinâmica, o universo é formado por um sistema e sua vizinhança. Um sistema aberto pode trocar matéria e energia com a vizinhança. Um sistema fechado só pode trocar energia, e por fim em um sistema isolado (adiabático) não há trocas de energia ou massa (ATKINS; JONES, 2006,).

O calor (q) é a energia que entra ou sai de um sistema termodinâmico, em virtude da diferença de temperatura entre o sistema e suas vizinhanças. Quando dois sistemas em temperaturas diferentes entram em contato, o sistema de maior temperatura transfere energia na forma de calor para o de menor temperatura, até que se atinja o equilíbrio térmico, quando ambos os sistemas adquirem a mesma temperatura.

Ao acessar o módulo "Comportamento ideal dos gases", o aluno visualiza sistema e vizinhança com 4 tipos de gases identificados pelas cores azul, branco, vermelho e laranja, passíveis de ocupar os espaços referentes às localidades correspondentes:

Quadro 1 - cores dos gases das respectivas vizinhança e sistema

\begin{tabular}{l|l|l}
\hline Localização & \multicolumn{2}{|c}{ Gases } \\
\hline Sistema & Azul & Branco \\
\hline Vizinhança & Vermelho & Laranja \\
\hline
\end{tabular}

Fonte: Autoria própria (2017).

Quando há energia suficiente para a realização da reação química, os dois gases de uma determinada localidade se juntam em uma única molécula diatômica representada no modelo de gás ideal. Por conseguinte, o efeito térmico desse 
processo depende das forças de interação entre as moléculas, sendo assim, uma energia de ativação deve ser atingida, o que ocorre ao se manipular os botões exotérmico e endotérmico. $O$ processo será exotérmico quando o sistema liberar energia para a vizinhança, e endotérmico quando ocorrer o contrário, ou seja, as moléculas da vizinhança liberando energia para o sistema.

No segundo módulo "Reação de Combustão" novamente apresentamos um sistema e sua vizinhança, e ao acessá-lo apresentam-se os botões: sistema fechado e combustão. $O$ sistema encontra-se adiabático, não há troca de energia, fazendo com que o comportamento dos gases do sistema seja independente da vizinhança.

Figura 5 - Reação de combustão referente ao segundo módulo

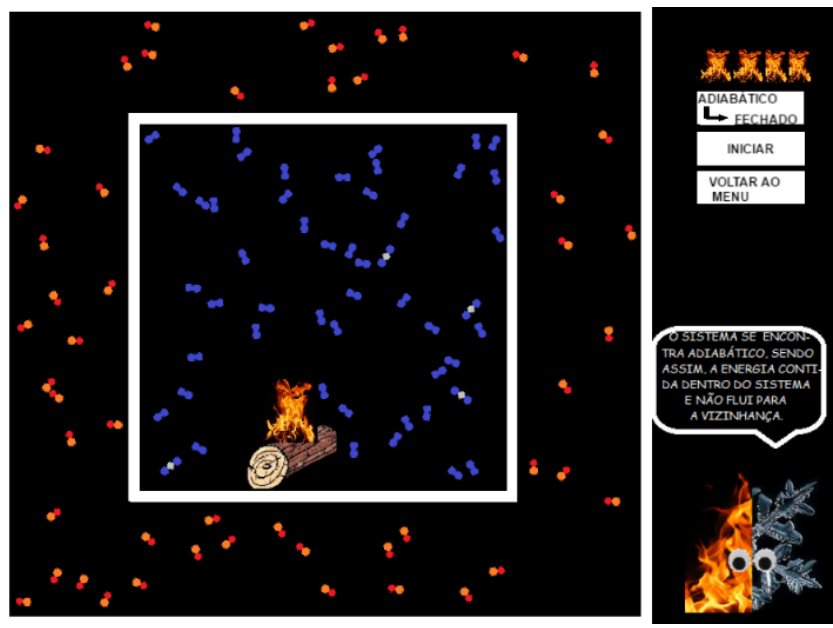

Fonte: Print Screen do aplicativo (2017)

O calor de combustão é a quantidade de calor liberada na queima de uma substância com o oxigênio. Sendo assim, ao clicar no botão de combustão, as moléculas começam a se unir como se estivessem formando $\mathrm{CO}_{2}$ (moléculas triatômicas azul-branco-azul), pois há a ruptura da cadeia carbônica na madeira e a oxidação de todos os átomos de carbono presentes na celulose.

A combustão só acontece enquanto há oxigênio disponível, caso contrário a reação não ocorre. Ao apertar o botão mesmo com oxigênio insuficiente há um aparecimento de chamas, porém sem reação química efetiva. Quando o botão de "sistema fechado" é clicado, as energias do sistema e vizinhança são trocadas, movimentando as moléculas. Em outras palavras, ocorre a passagem de energia pela parede com arte sugestiva, fazendo o gás de fora ter a mesma velocidade do gás de dentro.

O terceiro módulo apresenta um processo de solvatação que nada mais é do que um processo de dissolução, o qual envolve um gasto de energia para o rompimento das interações entre os íons do soluto e das interações entre moléculas de solvente. Essas duas etapas são, portanto, endotérmicas. Além disso, ocorre liberação de energia em função da formação de interações soluto-solvente (etapa exotérmica). Para que a dissolução ocorra, a energia envolvida nas etapas endotérmicas deve ser comparável à energia da etapa exotérmica. Dependendo da magnitude da energia envolvida nessas etapas, a dissolução pode ser endotérmica ou exotérmica (ATKINS; JONES, 2006). 
Figura 6 - Inserção do sal e reação de solvatação no sistema fechado.
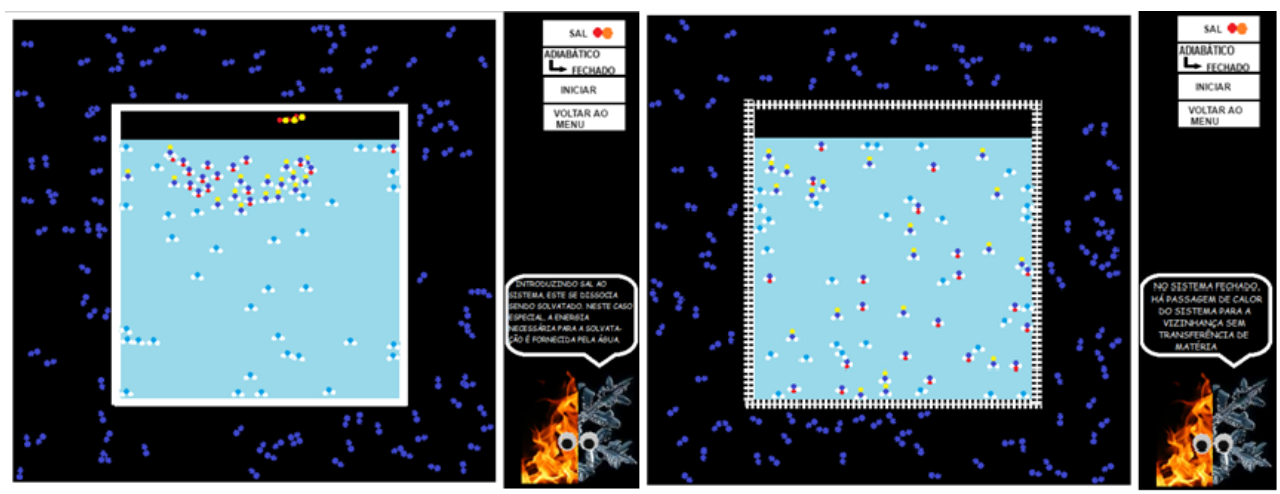

Fonte: Print Screen do aplicativo (2017).

O processo de inserção do sal dissolve os íons negativos e positivos que ficam envoltos pelas moléculas do solvente como em um processo simples de dissociação de um sal em água. Desse modo, quando o sal é dissociado em água, a atividade ou movimento desta, é reduzida consideravelmente. Como o sistema se encontra adiabático não ocorre troca de energia.

Ao ativar o "sistema fechado", a energia flui através da parede, porém sem trocar matéria, fazendo com que o gás da vizinhança resfrie até ter a mesma velocidade das partículas do sistema interno enquanto este se aquece, encontrando ambos o equilíbrio.

A atração virtual, a acessibilidade e a interatividade, fazem com que ocorra uma díade entre o computador e o aluno. Esse objeto foi elaborado na perspectiva de corresponder a um material educacional potencialmente significativo, que pretende facilitar a aprendizagem. $\mathrm{O}$ uso dos recursos tecnológicos na motivação dos alunos é de suma importância, dando aos professores a oportunidade de transformar a prática docente com atividades dinâmicas e motivadoras.

A partir disto, qualquer docente poderá utilizar esses mecanismos para o desenvolvimento do seu trabalho, preocupando-se com a interação que o aluno terá para com ele, a fim de que esse recurso venha contribuir para facilitar o processo de aprendizagem do estudante.

Ao longo do desenvolvimento deste objeto de aprendizagem, as principais dificuldades enfrentadas se apresentaram no uso da ferramenta GDevelop, como ausência de botões, comportamentos físicos e a transição de cena.

A ausência de botões foi um complicador pois o GDevelop não apresentava comando direto para uma imagem se tornar um botão. Sendo assim, foi necessária a criação de dois comportamentos em um objeto: comportamento arrastável para o programa identificar o pressionamento do botão/imagem e comportamento físico com o item de objeto fixado para o mesmo não ser arrastado devido ao primeiro comportamento. Alguns comportamentos físicos também não foram fiéis. No caso desse aplicativo, comportamentos completamente elásticos nas colisões eram necessários para simular sistemas ideais. Por algum motivo interno à física admitida pelo programa, a energia entre as colisões não era mantida. Assim fez-se necessário incluir reguladores de velocidade do tipo: $V_{\min }<V_{o b j}<V_{\max }$. Além destes, ao realizar a operação de transição de cena, os comandos da cena seguinte 
não vigoravam, o que tornou necessário unir três aplicativos ao invés de um aplicativo conter três cenas.

O objeto produzido tem por finalidade auxiliar o professor em processos de ensino-aprendizagem de conceitos termodinâmicos. Sua principal contribuição refere-se à inserção de aproximações visuais para os modelos submicroscópicos a serem desenvolvidos pelo professor em sala de aula. A existência dos aspectos visuais e a possibilidade do controle de variáveis que determinam o comportamento de entidades submicroscópicas foram enfatizadas ao longo do objeto de aprendizagem como forma do professor utilizar estratégias e discussões aliadas ao objeto para a produção de discussões sobre o uso de modelos na ciência. Neste sentido, cabe ressaltar o aspecto modelístico de tais aspectos visuais, o que fica a cargo do próprio professor, uma vez que tais discussões não foram incluídas no interior das proposições do assistente "Termo". A falta de criticidade em relação às animações propostas pode acarretar na aceitação das mesmas como uma fiel descrição da realidade submicroscópica, o que destoa de uma educação crítica em relação à natureza das entidades científicas.

Outro aspecto verificado como uma limitação do objeto proposto é seu caráter exclusivamente qualitativo. As animações propostas não trabalham com o aspecto quantitativo descritivo das transições de energia, o que se deve às limitações impostas pelo GDevelop durante a construção do objeto. Assim, tais aspectos também devem ser ressaltados pelo professor durante a utilização do objeto.

Tais limitações revelam a necessidade da inclusão de discussões pertinentes às mesmas no interior de um material auxiliar ao próprio objeto, o que se poderia denominar de "manual do professor" para a utilização do objeto. No entanto, dado o aspecto multifacetado dos objetos de aprendizagem, tem-se buscado uma perspectiva para tal manual que não restrinja a prática do professor, possibilitando que o objeto se manifeste como proposto anteriormente por Wiley (2000), um recurso modular, reestruturável e reutilizável.

\section{CONSIDERAÇÕES FINAIS}

O Objeto de Aprendizagem "Processos Termodinâmicos" foi construído com o intuito de auxiliar o professor nos processos de ensino-aprendizagem, facilitando a compreensão do aluno. Assim, visou-se a produção de animações interativas ou simulações interativas, remetendo a objetos apresentados pelas plataformas da Universidade do Colorado (o PHET-Colorado) e do Rived. Configurado em linguagem HTML 5, via GDevelop, "Processos Termodinâmicos" possibilita o controle de variáveis e consequentemente o curso do fenômeno em estudo a partir deste controle, remetendo a modelos teóricos submicroscópicos referentes a conceitos Químicos como forma de manipular variáveis e compreender a estruturação do próprio modelo em relação a suas proposições.

Procurando desenvolver um panorama sobre objetos de aprendizagem um levantamento bibliográfico foi feito para minimizar os equívocos encontrados nas abordagens e estratégias adotadas na forma da construção e aplicação do OA. O material instrucional, em anexo, faz um levantamento das dificuldades no ensinoaprendizagem dos conceitos presentes, propondo como e o que pode ser construído além de apresentar a utilização do objeto. O "Processos 
Termodinâmicos" é constituído por conteúdos auto-explicativos, sendo esses uma breve explicação do conteúdo, abordado pelo "Termo" um personagem/instrutor, presente em cada módulo. Estes conteúdos se relacionam entre si contribuindo para o processo de ensino-aprendizagem, pois as inter-relações em seus módulos permitem visualizar os conceitos de forma aplicada, ajudando o aluno a construir uma visão submicroscópica.

O uso combinado de texto e figuras animadas torna a informação mais fácil de ser memorizada. Além do que "Processos Termodinâmicos, com o uso de ferramentas multimídia, pode auxiliar no ensino e aprendizagem de química por desenvolver habilidades espaciais e a percepção de modelos. Junto a isso os professores de química podem criar situações reais que possam mostrar o universo macroscópico ao aluno acompanhado da simbologia química pertinente e, ao mesmo tempo, se utilizar de diferentes tipos de figuras, tais com a animação de computador e as simulações, presentes no objeto, com o objetivo de criar habilidades para a compreensão do nível molecular adquirindo um entendimento completo dos conteúdos.

Durante o desenvolvimento do Objeto de Aprendizagem, no GDevelop, várias limitações apareceram como: ausência de botões, não tendo um comando direto para elaboração de uma imagem se tornar um botão, falta de fidelidade na física, a energia entre as colisões não era mantida, falta de recursos de transição, os comandos da cena seguinte não vigoravam. Em vista disso, durante a elaboração do aplicativo foram feitos vários algoritmos para o comportamento mais ideal proposto pelo aplicativo, reguladores de velocidades, para reação química e mudança da parede.

Mesmo apresentando algumas dificuldades em sua construção o objeto de aprendizagem atingiu as expectativas, apresentando em seus módulos interatividade, conteúdos autoexplicativos para auxiliar os docentes no desenvolvimento de suas atividades de ensino-aprendizagem a partir de suas próprias necessidades facilitando a construção de modelos submicroscópicos. 


\title{
The construction of an interactive application applicable as didactic resource for thermodynamic concepts
}

\begin{abstract}
Referring to the animations / simulations present in the PHET-Colorado and Rived repositories, this work sought to produce a learning object, specifically animations / simulations, which pedagogically assists the teacher in teaching-learning activities of chemistry concepts. For this to be possible, through a research among the professors of the chemical and chemical engineering disciplines of higher education, a survey of the possible submicroscopic models that needed learning objects as auxiliaries in teachinglearning processes was carried out. Having raised the models in question, the following steps involved a process of research in search of a pedagogical and conceptual conception for learning objects as well as programming tools capable of sustaining such conceptions. Thus, using the GDevelop tool for its accomplishment, in the face of the presented reports the application "Thermodynamic Processes" was developed, being the same composed of three modules, offering concepts about: endothermic and exothermic processes, closed and adiabatic system, solvation, entropy and Enthalpy. The modules present selfexplanatory contents that are addressed by the "Term" of a character / instructor, who propose some relationships between the contents in the teaching-learning process and, therefore, are fully in line with the needs revealed by the teachers regarding the survey carried out.
\end{abstract}

KEYWORDS: Learning object, thermodynamic processes, GDevelop, TIC. 


\section{AGRADECIMENTOS}

Agradeço à Demanda Social UTFPR, campus de Apucarana, pelo financiamento da Bolsa referente ao projeto REA sem a qual este trabalho não teria sido possível ser realizado.

\section{REFERÊNCIAS}

ATKINS, P.W.; JONES, Loretta. Princípios de química: questionando a vida moderna e o meio ambiente. 3.ed. Porto Alegre: Bookman, 2006.

BENITE, A. M. C.; BENITE, C. R. M. O Computador no Ensino de Química: Impressões versus Realidade. Em Foco as Escolas Públicas da Baixada Fluminense. Ensaio: Pesquisas em Educação em Ciências v.10, n.2, 2008.

BETZ, M.; LIMA, I.; MUSSATTO, G. Dualidade onda-partícula: um objeto de aprendizagem baseado no interferômetro de Mach-Zehnder. Revista Brasileira Ensino de Física, v.31, n.3, 2009

COSTA, G. L. M.; FIORENTINI, D. Mudança da Cultura Docente em um Contexto de Trabalho Colaborativo de Introdução das Tecnologias de Informação e Comunicação na Prática Escolar. Bolema: Boletim de Educação Matemática, Rio Claro, v. 20, n. 27, p. 1-15, 2007.

COUTO, M. E. S.; COELHO, L. A. Políticas públicas para inserção das TIC nas escolas: algumas reflexões sobre as práticas. Colabor@ (Curitiba), v. 8, p. 1-11, 2013.

DOMINICI, T. P., et al. Atividades de observação e identificação do céu adaptadas às pessoas com deficiência visual. Revista Brasileira de Ensino de Física, v. 30, n. 4, p. 4501.1-4501.8, 2008.

DUARTE, S. E. Física para o ensino médio usando simulações e experimentos de baixo custo: um exemplo abordando dinâmica da rotação. Caderno Brasileiro do Ensino de Física, v. 29, n, especial, p. 525-542, 2012.

FERNANDES, G; RODRIGUES, A; FERREIRA, C. Módulos temáticos virtuais: uma proposta pedagógica para o ensino de ciências e o uso das TICs. Caderno Brasileiro de Ensino de Física, v. 32, n. 3, p. 934-962, 2015.

KEMEZINSKI, et al. (2012) "Metodologia para Construção de Objetos de Educação (SBIE 2012). Rio de Janeiro. 
LABURÚ, C. E.; SILVA, O. H. M; BARROS, M. A. Laboratório caseiro - Para-raios: um experimento simples e de baixo custo para a eletrostática. Caderno Brasileiro de Ensino de Física, v. 25, n. 1, p. 168-182, 2008.

LAGRECA, M. C. et al. Estudo do Lançamento Vertical: uma proposta de Ensino por meio de um objeto de aprendizagem. Caderno Brasileiro de Ensino de Física, v. 29, p. 543-561, 2012.

LOPES, D. P. M.; STEIN-BARANA, A. C. M.; MORENO, L. X. Construção de um guindaste eletromagnético para fins didáticos. Caderno Brasileiro do Ensino de Física, v. 26, n. 1, p. 199-207, 2009.

MISKULIN, R. G. S, et al. Identificação e análise das dimensões que permeiam a utilização das tecnologias de informação e comunicação nas aulas de matemática no contexto da formação de professores. Bolema: Boletim de Educação Matemática, v. 19, n. 26, 2006.

MUNHOZ, D. P.; STEIN-BARANA, A. C. M; LEME, C. S. Localizando pedacinhos do céu: constelações em caixas de suco. Caderno Brasileiro do Ensino de Física, v. 29, n. 1, p. 130-144, 2012.

PAGNOSSIN, I.R. et al. Objetos de aprendizagem interativos: participação e desempenho de estudantes de ciências. ETD Educação Temática Digital, v.16, n. 2, p. 362-380, 2014.

REIS, N. T. O., GARCIA, N. M. D., BALDESSAR, P. S. Métodos de projeção para observação segura de eclipses solares. Caderno Brasileiro do Ensino de Física, v. 29, n. 1, p. 81-113, 2012.

SALES, G.L. et al. Atividades de modelagem exploratória aplicada ao ensino de física moderna com a utilização do objeto de aprendizagem pato quântico. Revista Brasileira de Ensino de Física, v. 30, n. 3, 2008.

SARTORI, P. H. S., LORETO, É. L. S. Simulação da visão das cores: decodificando a transdução quântica-elétrica. Química nova na escola, v. 31, n.2, p. 55-57, 2008.

SOUSA, J. M.; MALHEIROS, A. P. S; FIGUEIREDO, N. Desenvolvendo práticas investigativas no Ensino Médio: o uso de um Objeto de Aprendizagem no estudo da Força de Lorentz. Caderno Brasileiro de Ensino de Física, v. 32, p. 988-1006, 2015. 
TAXINI, C. L. et al. Proposta de uma sequência didática para o ensino do tema "estações do ano" no ensino fundamental. Revista Ensaio, v.14, n. 1, p.81-97, 2012.

VERASZTO, E.V. et al. Proposta Para o Uso Didático da Computação Gráfica no Ensino de Conceitos da Física. Ciência e ensino, v.4, n. 1, 2015.

WARTHA, E. J.; REZENDE, D. B. Os níveis de representação no ensino de química e as categorias da semiótica de Peirce. Investigações em Ensino de Ciências, v. 16, n. 2, p. 275-290, 2011.

WILEY, D. A. Connecting learning objects to instructional design theory: A definition, a metaphor, and a taxonomy. 2000. Disponível em: http://reusability.org/read/. Acesso em: 21 de abril de 2016.

WILEY, D. A. Learning object design and sequencing theory. Doctoral dissertation, Brigham Young University. 2000.Disponível em: http://reusability.org/read/. Acesso em: 21 de abril de 2016.

Recebido: 29 mai. 2017

Aprovado: 21 ago. 2017

DOI: 10.3895/actio.v2n1.6792

Como citar:

RAMOS, L. W. C. et al. A construção de um aplicativo interativo como recurso didático para conceitos termodinâmicos. ACTIO, Curitiba, v. 2, n. 1, p. 474-492, jan./jul. 2017. Disponível em:

$<$ https://periodicos.utfpr.edu.br/actio>. Acesso em: XXX.

Correspondência:

Luara Wesley Candeu Ramos

Av. Minas Gerail, 2000, Vila São Miguel, Apucarana, Paraná, Brasil

Direito autoral: Este artigo está licenciado sob os termos da Licença Creative Commons-Atribuição 4.0

Internacional. 